(c) American Dairy Science Association, 2004.

\title{
Pregnancy Rates After Timed Al of Heifers Following Removal of Intravaginal Progesterone Inserts
}

\author{
I. D. Peeler, ${ }^{1}$ R. L. Nebel, ${ }^{1}$ R. E. Pearson, ${ }^{1}$ \\ W. S. Swecker, ${ }^{2}$ and A. Garcia ${ }^{2}$ \\ ${ }^{1}$ Department of Dairy Science and \\ ${ }^{2}$ Department of Large Animal Clinical Sciences, \\ Virginia Polytechnic Institute and State University, \\ Blacksburg 24061
}

\begin{abstract}
Reproductive performance of dairy heifers was compared for each of 2 synchronization protocols: The first group of 54 heifers was synchronized using intravaginal progesterone inserts (CIDR) plus estradiol cypionate (ECP) on $\mathrm{d} 0, \mathrm{PGF}_{2 \alpha}$ on $\mathrm{d} 7$, and ECP again on $\mathrm{d} 8$ (CIDR-ECP); a second group of 56 heifers was synchronized using CIDR and ECP on d $0, \mathrm{PGF}_{2 \alpha}$ on $\mathrm{d} 7$, and GnRH on d 9 (CIDR-GnRH). All heifers received timed artificial insemination (TAI) at 48, 56, or $72 \mathrm{~h}$ after CIDR removal on $d 7$. Pregnancy diagnosis was conducted by ultrasonography $32 \pm 1 \mathrm{~d}$ post AI to confirm pregnancy and at $60 \pm 1 \mathrm{~d}$ post AI to determine embryo survival. Ovaries were monitored by ultrasonography daily from $d 0$ to 7 and twice daily from $d 8$ to ovulation to examine emergence of a new wave of follicles, size of the ovulatory follicle, and timing of ovulation on 15 heifers per protocol. New follicular development was detected 3.7 $\pm 0.2 \mathrm{~d}$ after CIDR insertion. Heifers receiving CIDR-ECP had a shorter interval from CIDR removal to ovulation than heifers receiving CIDR-GnRH $(63.8 \pm 3.0$ vs. $71.6 \pm 2.3 \mathrm{~h}$, respectively); however, ovulation occurred $39.8 \pm 3.0 \mathrm{~h}$ after ECP or $23.6 \pm 2.3 \mathrm{~h}$ after GnRH. Diameters of ovulatory follicles did not differ between treatments. Overall pregnancy rate for synchronized heifers was $60.1 \%$, and embryo survival was $98 \%$. Pregnancy rate for heifers synchronized with CIDR-ECP was $63.0 \%$ and similar to that in heifers synchronized with CIDR-GnRH (57.1\%). Pregnancy rate was affected by time of AI for heifers synchronized using CIDR-ECP but not for those synchronized with CIDR-GnRH. Heifers in the CIDR-ECP group that were inseminated $56 \mathrm{~h}$ after CIDR removal had a higher pregnancy rate $(81.0 \%)$ compared with heifers inseminated $48(66.7 \%)$ or $72 \mathrm{~h}(50.0 \%)$ after CIDR removal. Either ECP or GnRH used in a CIDR-based TAI pro-
\end{abstract}

Received March 22, 2004.

Accepted June 2, 2004.

Corresponding author: R. L. Nebel; e-mail: rnebel@vt.edu.

gram in dairy heifers can achieve acceptable reproductive performance.

(Key words: intravaginal progesterone insert, timed artificial insemination, reproductive performance, dairy heifer)

Abbreviation key: CIDR = intravaginal progesterone insert, $\mathbf{E}_{\mathbf{2}}=$ estrogen, $\mathbf{E C P}=$ estradiol cypionate, $\mathbf{P}_{\mathbf{4}}=$ progesterone, $\mathbf{P R}=$ pregnancy rate, $\mathbf{T A I}=$ timed artificial insemination.

\section{INTRODUCTION}

On many dairy farms, heifers are not inseminated using AI due to their location on remote pastures and the extra effort that must be made for detection of estrus and AI by farm personnel. This has limited the use of AI in dairy heifers. Synchronization protocols that include timed artificial insemination (TAI) and achieve acceptable pregnancy rates (PR) could allow for increased use of AI in heifers. Using the Ovsynch protocol for TAI in dairy heifers decreased PR by 39 percentage units compared with AI following observed estrus (Pursley et al., 1995, 1997). Decreased PR of virgin heifers on Ovsynch protocols could be due to the number of follicular waves (Pursley et al., 1997) or inconsistent follicular wave emergence (Nebel and Jobst, 1998). Although the Ovsynch protocol has not produced acceptable PR in heifers, little research has been conducted to evaluate other methods of synchronization for TAI in dairy heifers.

Initial research was conducted using dairy heifers to evaluate the effectiveness of intravaginal progesterone $\left(\mathbf{P}_{4}\right)$ inserts also known as controlled internal drug release devices (CIDR) and reported an overall synchronization rate of $84 \%$ and a PR of $45 \%$ for the first $3 \mathrm{~d}$ of the AI period after CIDR removal and detected estrus (Lucy et al., 2001). Synchronization rate is enhanced when estrogen $\left(\mathbf{E}_{2}\right)$ is administered during $\mathrm{P}_{4}$ period (Hanlon et al., 1996, 1997). Many studies (Hanlon et al., 1996, 1997; Colazo et al., 2003, 2004) have demonstrated that exogenous $\mathrm{E}_{2}$ is effective when used at the 
CIDR-ECP protocol:

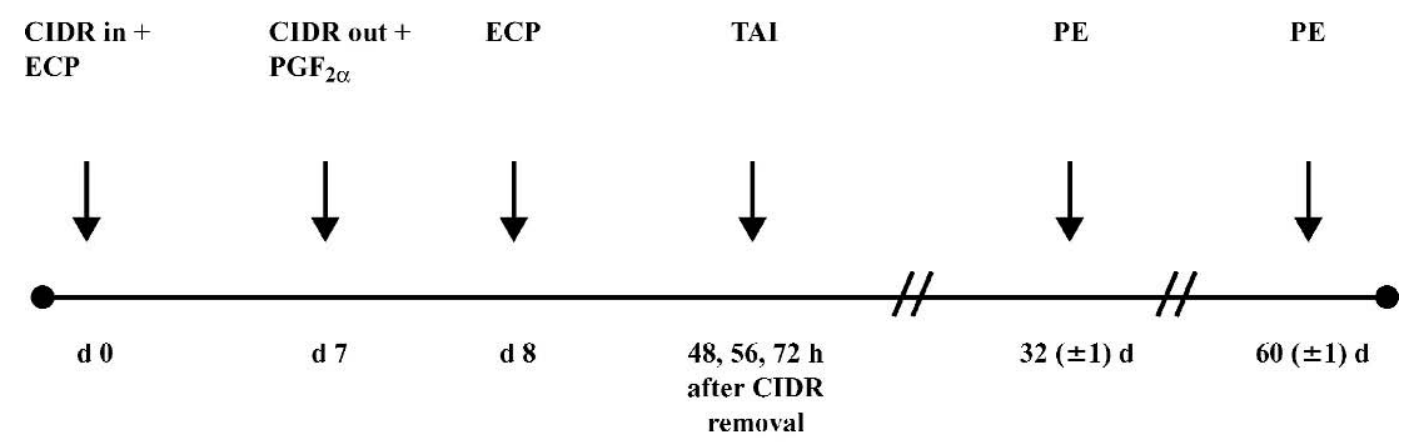

CIDR-GnRH protocol:

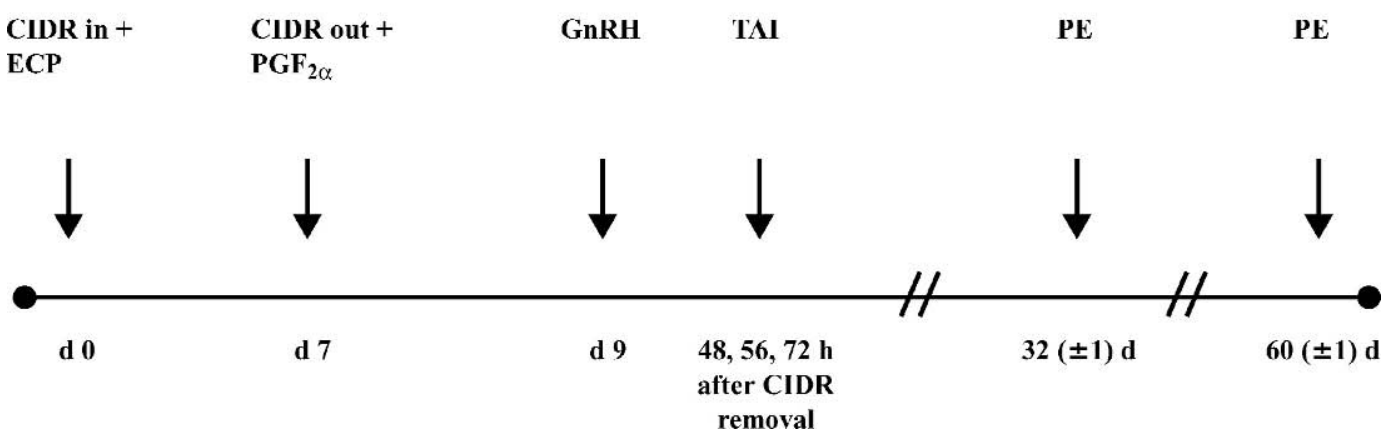

Figure 1. Experimental protocol used for dairy heifers synchronized with intravaginal progesterone inserts (CIDR) combined with estradiol cypionate (ECP) at $24 \mathrm{~h}$ or $\mathrm{GnRH}$ at $48 \mathrm{~h}$ after CIDR removal, followed by AI at 48, 56, or $72 \mathrm{~h}$ after CIDR removal. Following timed AI (TAI), pregnancy exams $(\mathrm{PE})$ were performed at $32( \pm 1) \mathrm{d}$ and $60( \pm 1) \mathrm{d}$ post $\mathrm{AI}$ to confirm pregnancy and determine embryo survival rate.

beginning or end of a CIDR synchronization protocol. Although abundant research has been published on the subject of synchronization of estrus using CIDR inserts, little research has been conducted using the CIDR insert with TAI in dairy heifers.

The objectives of this study were to determine follicular wave emergence following an estradiol cypionate (ECP) injection at the time of CIDR insertion and to compare the response of ECP given $24 \mathrm{~h}$ or $\mathrm{GnRH}$ given $48 \mathrm{~h}$ after CIDR removal on ovulation rate, time of ovulation, diameter of the ovulatory follicle, and PR after TAI following CIDR removal in dairy heifers.

\section{MATERIALS AND METHODS}

\section{Heifers and Treatment Protocols}

The trial was conducted from August 2002 to March 2004 using heifers $(n=110)$ from the Virginia Tech Dairy Center. Heifers were between 14 and 19 mo of age at the start of the synchronization protocols. Jersey ( $\mathrm{n}=39)$ and Holstein $(\mathrm{n}=71)$ heifers were managed together on pastures of orchardgrass and fescue. Heifers were fed corn silage, concentrate, 2:1 mineral, and mixed orchardgrass hay during the winter.
Heifers were randomly assigned to a synchronization protocol without regard to the stage of the estrous cycle at initiation of synchronization (Figure 1). Within the 2 synchronization protocols, heifers were randomly assigned to 48 or $72 \mathrm{~h} \mathrm{TAI}$; however, a subset of heifers was assigned randomly to a synchronization protocol but inseminated $56 \mathrm{~h}$ after CIDR removal. All heifers $(\mathrm{n}=110)$ received a CIDR containing $1.38 \mathrm{~g}$ of $\mathrm{P}_{4}$ (EaziBreed CIDR, Pfizer, Inc., New York, NY) and a 1-mg i.m. injection of ECP (ECP, Pfizer, Inc.) at time of device insertion ( $d 0$ ). On $d 7$, the CIDR device was removed and a 25-mg i.m. injection of $\mathrm{PGF}_{2 \alpha}$ (Lutalyse, Pfizer, Inc.) was administered. One group of 54 heifers was assigned to receive a $0.5-\mathrm{mg}$ i.m. injection of ECP 24 $\mathrm{h}$ after CIDR removal, and this synchrony group was labeled CIDR-ECP. A second group of 56 heifers was assigned to receive a $100-\mu \mathrm{g}$ i.m. injection of $\mathrm{GnRH}$ (Cystorelin, Merial Ltd., Iselin, NJ) $48 \mathrm{~h}$ after CIDR device removal and was labeled the CIDR-GnRH group. Heifers were not observed for estrus at any time during the study. Proven sires of known fertility were obtained from a single AI organization; inseminations were performed by experienced AI technicians. 


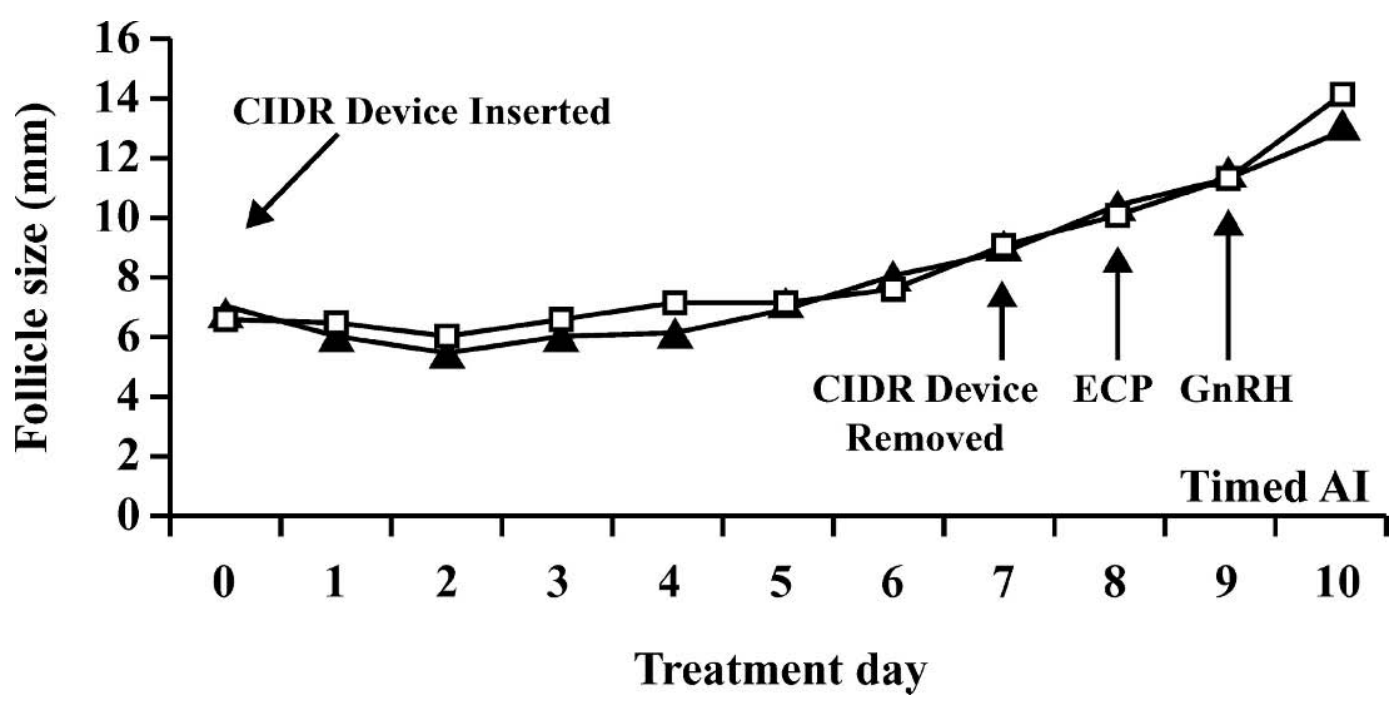

Figure 2. Average follicle size of largest or dominant follicle for dairy heifers synchronized with intravaginal progesterone inserts (CIDR) combined with estradiol cypionate (ECP) $(\mathbf{\Delta})$ at $24 \mathrm{~h}$ or GnRH $(\square)$ at $48 \mathrm{~h}$ after CIDR removal, followed by AI at 48,56 , or $72 \mathrm{~h}$ after CIDR removal. Standard errors for ECP and GnRH groups were \pm 0.45 and \pm 0.43 , respectively.

In a subset of heifers $(\mathrm{n}=30)$, ovarian ultrasonographic examinations were performed daily from $\mathrm{d} 0$ to 7 and twice daily from $\mathrm{d} 8$ to ovulation to monitor follicular development, emergence of a new wave of follicular development, the size of the ovulatory follicle, and ovulation.

Pregnancy diagnosis was performed by ultrasonography with a 7.4-MHz broadband curved-array transducer (Sonosite 180PLUS, SonoSite, Inc., Bothell, WA) at $32 \pm 1 \mathrm{~d}$ following AI. A second pregnancy diagnosis was performed $60 \pm 1 \mathrm{~d}$ post AI to confirm pregnancy and determine embryo survival rate. The PR was defined as the number of heifers pregnant divided by the number of heifers synchronized. The embryo survival rate was the number of heifers diagnosed open $60 \pm 1 \mathrm{~d}$ post AI divided by the total number of heifers diagnosed pregnant $32 \pm 1 \mathrm{~d}$ post AI.

\section{Data and Statistical Analysis}

Interval from CIDR removal to ovulation and diameter of the largest or dominant follicle were measured on the initial 30 heifers. One-way ANOVA was used to determine differences in the means for heifers treated with CIDR-ECP $(\mathrm{n}=15)$ and CIDR-GnRH $(\mathrm{n}=15)$.

First-service PR was analyzed using logistic regression (SAS Institute, Inc., Cary, NC) in a model that included month by year insemination, AI technician, breed, and AI time. Months were combined to avoid extremely small categories. Time of AI subclasses were evaluated using linear contrasts to test treatment, insemination at $56 \mathrm{~h}$ vs. the average of 48 and $72 \mathrm{~h}$ insemi- nation times within each treatment, and 48 vs. $72 \mathrm{~h}$ within treatment. Results of the logistic analyses were presented as odds ratios and $95 \%$ confidence intervals. Odds ratios, which are a measure of the strength of association between explanatory and response variables, were interpreted as odds of pregnancy occurring for a particular explanatory variable category relative to the baseline category for that variable when the other explanatory variables were controlled in the model: 1 , no effect on pregnancy; $>1$, increased probability of pregnancy; and $<1$, decreased probability of pregnancy compared with the baseline category. The $95 \%$ confidence intervals show the precision of the odds ratio estimates. A confidence interval that contained the value of 1 suggested no significant difference between the category and the baseline category for that variable. Tests were considered different at the $P \leq 0.05$ level and tendencies at the $P \leq 0.1$ level.

\section{RESULTS AND DISCUSSION}

\section{Follicular Development and Ovulation}

A new wave of follicular development was detected on average $3.7 \pm 0.2 \mathrm{~d}$ after ECP injection at CIDR insertion. No difference in follicular development between the 2 synchronization protocols was detected, or expected, because treatments were identical up to that point (Figure 2). Heifers given ECP $24 \mathrm{~h}$ after CIDR removal had a shorter $(P \leq 0.05)$ interval from CIDR removal to ovulation than heifers given $\mathrm{GnRH}(63.8 \pm$ 3.0 and $71.6 \pm 2.3 \mathrm{~h}$, respectively); however, relative to 
Table 1. Mean ( \pm SE) follicular activity for dairy heifers synchronized with intravaginal progesterone inserts (CIDR) combined with estradiol cypionate (ECP) at $24 \mathrm{~h}$ or $\mathrm{GnRH}$ at $48 \mathrm{~h}$ after CIDR removal followed by AI at 48,56 , or $72 \mathrm{~h}$ after CIDR removal.

\begin{tabular}{lcc}
\hline & $\begin{array}{l}\text { ECP } \\
\text { treatment } \\
(\mathrm{n}=15)\end{array}$ & $\begin{array}{l}\text { GnRH } \\
\text { treatment } \\
(\mathrm{n}=15)\end{array}$ \\
\hline $\begin{array}{l}\text { Days to new follicular wave } \\
\begin{array}{c}\text { Interval from CIDR device } \\
\text { removal to ovulation }\end{array}\end{array}$ & $3.9 \pm 0.9$ & $3.6 \pm 1.0$ \\
$\begin{array}{c}\text { Diameter of dominant } \\
\text { follicle (mm) }\end{array}$ & $13.0 \pm 0.5$ & $71.6 \pm 2.3$ \\
Ovulation rate $(\%)$ & 100 & $14.1 \pm 0.4$ \\
\hline
\end{tabular}

${ }^{1}$ Means are statistically different $(P<0.05)$.

the hormone injection after CIDR removal, ovulation occurred after $39.8 \pm 3.0 \mathrm{~h}$ in heifers given ECP and after $23.6 \pm 2.3 \mathrm{~h}$ for heifers given GnRH. Ovulation rate $(100 \%)$ and diameter of ovulatory follicle $(13.0 \pm$ 0.5 and $14.0 \pm 0.4$, respectively) did not differ $(P>0.05)$ between CIDR-ECP and CIDR-GnRH treatment groups, respectively (Table 1 ).

Regardless of treatment with CIDR-ECP or CIDRGnRH, all heifers (30/30) in the subset undergoing daily ultrasonography ovulated. Treatment with GnRH induces acute release of $\mathrm{LH}$ and $\mathrm{FSH}$; if the dominant follicle present at the time of GnRH injection has expressed LH receptors, it will ovulate (Colazo et al., 2004); ovulation occurred at $23.6 \pm 2.3 \mathrm{~h}$ for heifers receiving the CIDR-GnRH treatment. In contrast, ad- ministration of exogenous $\mathrm{E}_{2}$ has been shown to synchronize follicular wave emergence regardless of stage of the dominant follicle when treatment was initiated (Bó et al., 1994; Adams et al., 1995). Mechanisms responsible for $\mathrm{E}_{2}$-induced synchronization of follicular growth appear to involve suppression of plasma FSH concentrations by inhibition from the dominant follicle, followed by synchronous resurgence of FSH after atresia or removal of the dominant follicle (Bó et al., 1994, 2000 ), and this is presumably the mechanism employed by the initial ECP injection at CIDR insertion. However, the $0.5 \mathrm{mg}$ ECP treatment $24 \mathrm{~h}$ after CIDR removal assisted in follicular growth and maturation without directly inducing an LH surge. Therefore, the time from ECP injection to ovulation was much longer $(39.8 \pm 3.0 \mathrm{~h})$ in heifers given CIDR-ECP and was the reason for administration of ECP $24 \mathrm{~h}$ before $\mathrm{GnRH}$ in the protocol design.

\section{Pregnancy Rate at First Insemination}

The effects of synchronization treatment, breed, or AI technician did not significantly influence first-service PR (Table 2). The first-service PR for Jersey heifers $(64.1 \%)$ tended $(P<0.1)$ to be higher than that of Holstein heifers $(57.7 \%)$. Generally, first service PR did not differ $(P>0.1)$ across months of insemination, but numbers of observations for those subgroups were only 10 to 18 inseminations (Table 2). However, heifers in-

Table 2. Logistic binomial regression for effects of month and year of AI, breed, and AI technician on pregnancy rate $(\mathrm{PR})$ of dairy heifers synchronized with intravaginal progesterone inserts (CIDR) combined with estradiol cypionate (ECP) at $24 \mathrm{~h}$ or $\mathrm{GnRH}$ at $48 \mathrm{~h}$ after CIDR removal followed by $\mathrm{AI}$ at 48,56 , or $72 \mathrm{~h}$ after CIDR removal.

\begin{tabular}{|c|c|c|c|c|}
\hline Category & AI (no.) & PR (\%) & $\begin{array}{l}\text { Odds } \\
\text { ratio }^{1}\end{array}$ & $\begin{array}{l}\text { 95\% Confidence } \\
\text { interval }^{2}\end{array}$ \\
\hline \multicolumn{5}{|l|}{ Month and year of AI } \\
\hline August-September 2002 & 15 & 73.3 & 1.00 & $\ldots$ \\
\hline October-November 2002 & 15 & 73.3 & 0.56 & $(0.07,4.25)$ \\
\hline February 2003 & 10 & 30.0 & $0.07^{3}$ & $(0.01,0.69)$ \\
\hline March 2003 & 10 & 80.0 & 2.08 & $(0.25,17.02)$ \\
\hline May 2003 & 18 & 66.7 & 0.72 & $(0.14,3.84)$ \\
\hline August-September 2003 & 15 & 53.3 & 0.34 & $(0.06,1.90)$ \\
\hline November 2003 & 14 & 57.1 & 0.45 & $(0.08,2.52)$ \\
\hline January 2004 & 13 & 38.5 & 0.20 & $(0.02,1.98)$ \\
\hline \multicolumn{5}{|l|}{ Breed } \\
\hline Jersey & 39 & 64.1 & 1.00 & $\ldots$. \\
\hline Holstein & 71 & 57.7 & 0.73 & $(0.56,2.09)$ \\
\hline \multicolumn{5}{|l|}{ AI technician } \\
\hline 1 & 67 & 56.7 & 1.00 & ... \\
\hline 2 & 37 & 70.3 & 2.02 & $(0.67,6.07)$ \\
\hline 3 & 6 & 33.3 & 0.62 & $(0.04,10.14)$ \\
\hline
\end{tabular}

${ }^{1}$ Odds ratio is the estimated odds of becoming pregnant for a heifer AI in a particular category relative to the baseline category for that variable for the effects of the other explanatory variables shown. Odds ratio $=1$ : no effect of pregnancy; $>1$ : increased probability of pregnancy; and $<1$ : decreased probability of pregnancy compared with the baseline category.

${ }^{2}$ When CI encompasses 1 , the odds ratio is not significant.

${ }^{3} P<0.05$. 


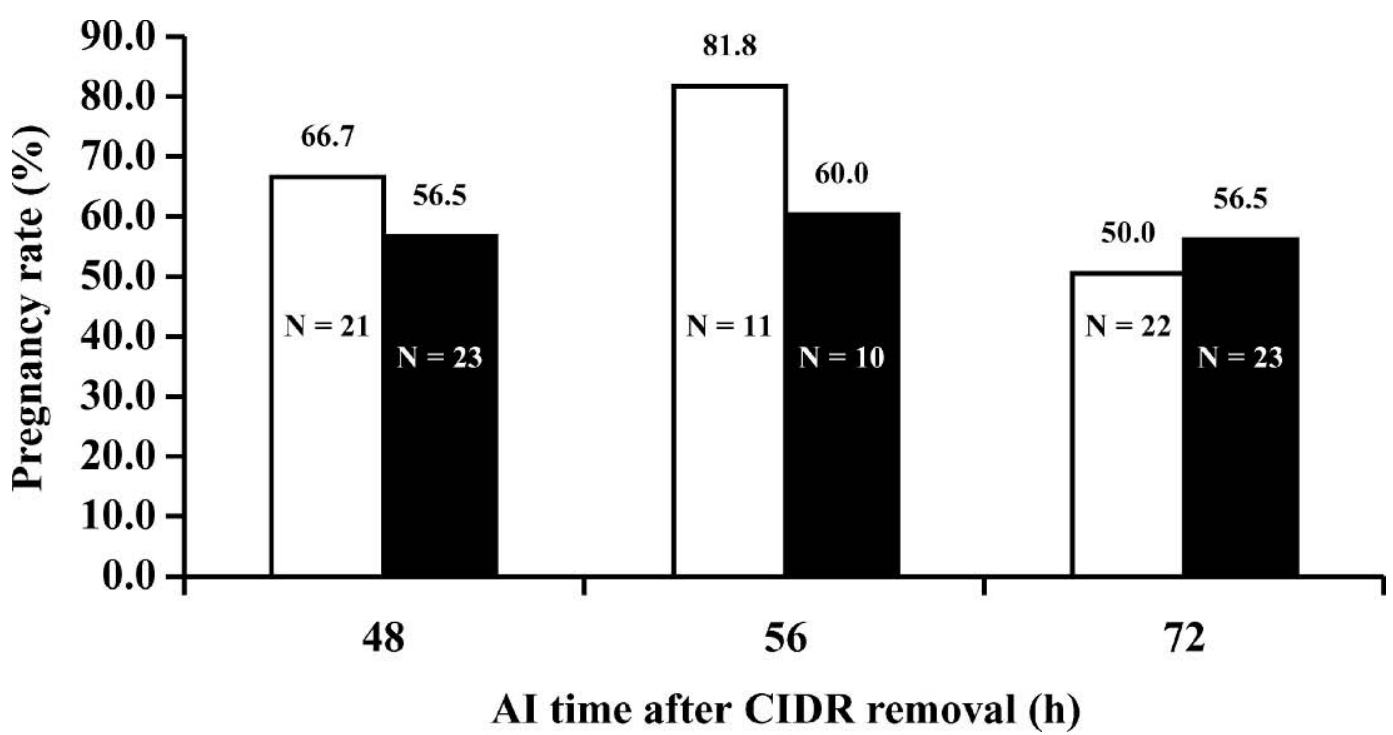

Figure 3. First-service pregnancy rate for dairy heifers synchronized with intravaginal progesterone inserts (CIDR) combined with estradiol cypionate (ECP) ( $\square$ ) at $24 \mathrm{~h}$ or GnRH (ם) at $48 \mathrm{~h}$ after CIDR removal, followed by AI at 48, 56, or $72 \mathrm{~h}$ after CIDR removal.

seminated in February 2003 did have a lower probability of pregnancy (odds ratio $=0.07 ; P<0.05$ ) compared with heifers inseminated during August and September 2002, the baseline comparison group. The low PR for heifers inseminated during February 2003 was most likely due to extremely cold and wet environmental conditions during that period. All heifers were maintained on a dry lot without housing throughout the study. The overall PR for synchronized heifers was $60.0 \%$. The first-service PR for heifers in the CIDRECP group $(63.0 \%)$ tended $(P<0.1)$ to be higher than the PR of heifers in the CIDR-GnRH group (57.1\%). The first-service PR differed $(P<0.05)$ by AI time for heifers in the CIDR-ECP synchronized group. Heifers inseminated $56 \mathrm{~h}$ following CIDR removal had a higher PR $(81.8 \%)$ than heifers inseminated 48 or $72 \mathrm{~h}(66.7$ vs. $50.0 \%$, respectively) after CIDR removal; however, differences in PR for heifers inseminated at 48 or $72 \mathrm{~h}$ following CIDR removal were not significantly different. The first-service PR did not differ among AI times in the CIDR-GnRH group (Figure 3). The embryo survival rate for CIDR-ECP-treated heifers was 98\%, whereas all CIDR-GnRH-treated heifers pregnant at d $32( \pm 1)$ were pregnant at $\mathrm{d} 60( \pm 1)$.

In a recent study (Lucy et al., 2001), the synchronization rate measured in a 3 -d period of detecting estrus was higher $(P<0.05)$ in dairy heifers that received a combination of CIDR insert and $\mathrm{PGF}_{2 \alpha}(84 \%)$ compared with heifers receiving only $\mathrm{PGF}_{2 \alpha}(57 \%)$. The conception rate was higher in heifers receiving only $\mathrm{PGF}_{2 \alpha}(65 \%)$ vs. heifers receiving CIDR inserts and $\mathrm{PGF}_{2 \alpha}(54 \%)$. The PR, however, was highest for heifers receiving CIDR inserts and $\mathrm{PGF}_{2 \alpha}(45 \%)$ compared with heifers inseminated following $\mathrm{PGF}_{2 \alpha}$ treatment and visual detection of estrus (37\%). Another study (Macmillan et al., 1993) observed that $49 \%$ of heifers treated with a CIDR-based synchronization protocol combined with TAI were visually detected in estrus within $48 \mathrm{~h}$ after CIDR removal, and another $41 \%$ were visually detected in estrus 49 to $72 \mathrm{~h}$ following CIDR removal.

\section{Summary}

Timing of insemination markedly influenced $(P<$ 0.05) PR for heifers in the CIDR-ECP treatment group. Heifers in the CIDR-ECP treatment group inseminated $56 \mathrm{~h}$ after CIDR removal had a higher PR (81.0\%) compared with heifers inseminated $48(66.7 \%)$ or $72 \mathrm{~h}$ (50.0\%) after CIDR removal. Timing of insemination did not influence $(P<0.1)$ PR for heifers in the CIDRGnRH treatment group. The interval from CIDR removal to ovulation was approximately $8 \mathrm{~h}$ shorter for heifers receiving ECP (63.8 vs. $71.6 \mathrm{~h}$ ). Therefore, using the difference in ovulation time after CIDR removal as the reference for TAI, the ideal AI time of ECP-treated heifers would be $52 \mathrm{~h}$ after CIDR removal compared with $60 \mathrm{~h}$ for heifers receiving GnRH $48 \mathrm{~h}$ following CIDR removal. In conclusion, administration of ECP $24 \mathrm{~h}$ after CIDR removal resulted in PR comparable to that obtained in heifers administered GnRH $48 \mathrm{~h}$ after CIDR removal. Therefore, either CIDR-ECP or CIDRGnRH may be used to synchronize ovulation in a CIDRbased TAI program in dairy heifers. To obtain the highest PR with TAI in heifers, the use of CIDR inserts and 
ECP $24 \mathrm{~h}$ after CIDR removal is recommended, with AI occurring approximately $52 \mathrm{~h}$ after CIDR removal or $32 \mathrm{~h}$ after ECP administration. In contrast, because of the later injection of $\mathrm{GnRH}$ and associated later ovulation relative to $\mathrm{CIDR}$ removal, $\mathrm{AI}$ is recommended at approximately $60 \mathrm{~h}$ after CIDR removal or $12 \mathrm{~h}$ after GnRH administration.

\section{ACKNOWLEDGMENTS}

This research was made possible by the partial financial assistance from the Virginia Agriculture Council, Project 406, (Richmond, VA), donation of semen by Select Sire, Inc. (Plain City, OH), and the donation of Lutalyse and ECP by Pfizer, Inc. (New York, NY). The authors gratefully thank Ramanathan Kasimanickam and Bennet Cassell for all their technical contributions and are grateful to the employees at the Virginia Tech Dairy Center for their help and patience during the study. Assistance provided by Amy Dorente, Jeff Cornwell, Rebecca Cornman-Daubert, Beau Knight, Matt Mink, Chase Scott, Aaron Tompkins, and Alex Welsh during the collection period is sincerely appreciated.

\section{REFERENCES}

Adams, G. P., M. Caccia, M. Martínez, R. A. Pierson, and R. J. Mapletoft. 1995. Ovarian follicular wave emergence after treatment with progesterone and estradiol in cattle. Anim. Reprod. Sci. 39:193-204.

Bó, G. A., G. P. Adams, R. A. Pierson, H. E. Tribulo, M. Caccia, and R. J. Mapletoft. 1994. Follicular wave dynamics after estradiol$17 \beta$ treatment of heifers with or without a progestogen implant. Theriogenology 41:1555-1569.

Bó, G. A., D. R. Bergfelt, R. A. Pierson, G. P. Adams, and R. J. Mapletoft. 2000. Local versus systemic effects of exogenous estra- diol on ovarian follicular dynamics in heifers with progestogen ear implants. Anim. Reprod. Sci. 59:141-157.

Colazo, M. G., J. P. Kastelic, and R. J. Mapletoft. 2003. Effects of estradiol cypionate (ECP) on ovarian follicular dynamics, synchrony of ovulation, and fertility in CIDR-based, fixed-timed AI programs in beef heifers. Theriogenology 60:855-865.

Colazo, M. G., J. P. Kastelic, M. F. Martinez, P. R. Whittaker, R. Wilde, J. D. Ambrose, R. Corbett, and R. J. Mapletoft. 2004. Fertility following fixed-time AI in CIDR-treated beef heifers given $\mathrm{GnRH}$ or estradiol cypionate and fed diets supplemented with flax seed or sunflower seed. Theriogenology 61:1115-1124.

Hanlon, D. W., N. B. Williamson, J. J. Wichtel, I. J. Steffert, A. L. Craigie, and D. U. Pfeiffer. 1996. The effect of estradiol benzoate administration on estrous response and synchronization pregnancy rate in dairy heifers after treatment with exogenous progesterone. Theriogenology 45:775-785.

Hanlon, D. W., N. B. Williamson, J. J. Wichtel, I. J. Steffert, A. L. Craigie, and D. U. Pfeiffer. 1997. Ovulatory responses and plasma luteinizing hormone concentration in dairy heifers after treatment with exogenous progesterone and estradiol benzoate. Theriogenology 47:963-975.

Lucy, M. C., H. J. Billings, W. R. Butler, L. R. Ehnis, M. J. Fields, D. J. Kesler, J. E. Kinders, R. C. Mattos, R. E. Short, W. W. Thatcher, R. P. Wettemann, J. V. Yelich, and H. D. Hafs. 2001. Efficacy of an intravaginal progesterone insert and an injection of $\mathrm{PGF}_{2 \alpha}$ for synchronizing estrus and shortening the interval to pregnancy in postpartum beef cows, peripubertal beef heifers, and dairy heifers. J. Anim. Sci. 79:982-995.

Macmillan, K. L., and A. J. Peterson. 1993. A new intravaginal progesterone-releasing device for cattle (CIDR-B) for estrous synchronization, increasing pregnancy rates and the treatment of postpartum anestrus. Anim. Reprod. Sci. 33:1-25.

Nebel, R. L., and S. M. Jobst. 1998. Evaluation of systematic breeding programs for lactating dairy cows. J. Dairy Sci. 81:1169-1174.

Pursley, J. R., M. O. Mee, and M. C. Wiltbank. 1995. Synchronization of ovulation in dairy cows using $\mathrm{PGF}_{2 \alpha}$ and $\mathrm{GnRH}$. Theriogenology 44:915-923.

Pursley, J. R., M. C. Wiltbank, J. S. Stevenson, J. S. Ottobre, H. A. Garverick, and L. L. Anderson. 1997. Pregnancy rates per artificial insemination for cows and heifers inseminated at a synchronized ovulation or synchronized estrus. J. Dairy Sci. 80:295-306.

SAS User's Guide. 1999. Statistics, Version 8, Edition 1. SAS Inst., Inc., Cary, NC. 